Mr. Henry concluded that the present position of soil mechanics aspects of foundation design is reasonably satisfactory. Where soil conditions are straightforward or the structure is not large-for example, a domestic house or a small retaining wall-then simple investigations of the site and tests coupled with elementary soil mechanics theories are sufficient for practical work. On the other hand, considerable practical experience and theoretical knowledge is required where soil conditions beneath projected important structures are complex, and the interpretations of investigations and recommendations are best placed in the hands of specialists.

The engineer will never be able to escape the fact that soil is the most variable material with which he has to deal, and even where a mass of soil is apparently of uniform type, its physical properties may vary considerably. Apart from general changes in physical properties which may occur across a site, there are innumerable local variations which would entail much work to determine and take into account directly. In suitable cases such local variations can be catered for in the design of important structures by means of a coefficient of variation, in the nature of a factor of safety, based on the magnitude and frequency of properties revealed by soil mechanics tests.

The symposium was attended by a large audience and admirably exemplified the value of joint meetings between sections, a feature that becomes yearly more desirable with the rapidly increasing degree of inter. digitation of the different sciences. Interest in the meeting was accentuated by the kindness of Engineering in providing pre-prints of the several papers, and of the Soil Mechanics Department of the University of Bristol in furnishing apparatus for purposes of demonstration.

F. H. EDMUNDs

\title{
LIGHTING AND VISION
}

\section{$\mathrm{T}$} HE discussion on lighting and vision in Section I (Physiology) of the British Association during the recent Bristol meeting was opened by four speakers whose papers dealt with some important aspects of the subject.

In the first paper, H. C. Weston, director of the Medical Research Council's Group for Research in Occupational Optics, gave a brief account of some of the studies of human responses to varieties of lighting that have been made in recent decades with the object of providing scientific knowledge as a basis for planning lighting, particularly for building interiors. A number of these studies which have influenced present concepts of good lighting practice have been made in Great Britain, under the æois of the Medical Research Council and the Department for Scientific and Industrial Research. They were primarily prompted by concern for the welfare of people at work and for their occupational efficiency.

Thus, in the early twenties, Elton, Weston and Wyatt each studied the effects of lighting upon the performance of weavers, which was shown to vary with the amount of illumination available up to about $30 \mathrm{~lm} . / \mathrm{ft}^{2}{ }^{2}$. Weston and Taylor varied the illumination provided for printing compositors, and found that the rate and accuracy of working was proportional to the logarithm of the illumination value up to a level of $25 \mathrm{Im}$./ft. ${ }^{2}$. They also showed that if the lamps used were so placed as to be glaring, work was impeded and the effectiveness of a given value of illumination on the work was reduced.

McDermott determined the desirable illumination for the work of typists, and Adams studied the response of persons doing visually unexacting work under different conditions of lighting. By such fieldstudies in occupations, chosen because their visual demands seem typical of whole classes of occupations, it was hoped to determine a scale of values of illumination adequate on physiological and psychological grounds for diverse purposes. This is a lengthy and difficult procedure, and a more fundamental approach was suggested by Beuttell in 1933. Pointing out that the visibility of all objects depends on certain of their characteristics, chiefly their size, contrast and luminance, he proposed that the relations between these variables be ascertained experimentally, so that levels of illumination could be computed for any visual task the critical components of which could be measured.

Using a suitable series of standardized tasks, Weston determined these basic relations, and his data are widely used internationally in prescribing illumination for good visual performance. He has also shown the effect of age upon the performance of these visual tasks and how it varies with different levels of illumination.

A much studied aspect of lighting is glare. Current rules of practice for the avoidance of this evil are due largely to the experimental studies of Stiles and, more recently, of Hopkinson and others at the Building Research Station. Responses to a variety of other features of lighting have been and still are being studied scientifically. Although recent advances in knowledge of lighting requirements, as well as in lighting techniques, are being applied fairly extensively, there is no doubt that the present lighting of many homes, schools, hospitals, offices, factories and other places is poor ; not very rarely it is almost incredibly bad.

The investigations described by W. R. Stevens, head of the Illumination Group, General Electric Company's Research Laboratories, Wembley, were made by Foxell and Stevens to explore the dependence of the capacity for seeing detail upon the luminance of the object looked at and the luminance of fields of different size surrounding the object. Lythgoe (1932) showed that, except at low values of test-object luminance, the visual acuity attainable is better when the surrounding field of view has a luminance not very much below that of the test-object than when this field has zero or almost zero luminance.

On the basis of this finding, it has been widely held that lighting for good seeing should brighten the whole apparent environment almost as much as it brightens the given object of attention. However, Lythgoe did not study the effect upon acuity of luminous surrounds of test-objects when the surrounds do not entirely fill the visual field. Foxell and Stevens have done this, and have also measured acuity at higher values of luminance than Lythgoe used. 'They made, altogether, about 100,000 observations, using a Landolt broken ring as test-object The ring was presented in contrast with a central field subtending an angle of $0.5^{\circ}$ at the eyes of the 
observers. The luminance of this field was varied up to a value of $10,000 \mathrm{ft}$. L. Visual acuity was measured with the remainder of the visual field dark and also when the small central field was surrounded with a more extensive bright field. Measurements were made using three such surrounds the angular subtense of which was, respectively, $6^{\circ}, 38^{\circ}$ and $120^{\circ}$. The effect of the bright surround was studied when its luminance was made either equal to or different from the luminance of the central field.

Tt was found that at low luminances of the central field, visual acuity was unaffected by the size and luminance of the surround except, as Lythgoe also found, that it was reduced when the surround luminance exceeded that of the detail to be detected. At all luminances of the central field exceeding $1 \mathrm{ft}$. L., the presence of a luminous surround improved acuity, and the best effect was observed when the central field and the surround were matched in luminance. The beneficial effect of a bright surround upon acuity was not significantly greater with surround sizes of $38^{\circ}$ and $120^{\circ}$ than with the $6^{\circ}$ size. Although this comparatively small luminous surround suffices for the achievement of high acuity, in ordinary circumstances a general distribution of light is usually necessary in buildings because detail has to be seen in many positions.

Foxell and Stevens found that maximum acuity was reached at a central field luminance of about $1,000 \mathrm{ft}$. L., with a $6^{\circ}$ surround of equal luminance. At higher levels of luminance and for all surround conditions, acuity decreased. Some experiments were also made with equal-luminance red-green combinations of test-object and central field to determine the acuity due to colour contrast. Quite high values of acuity were attained, but the maximum was inferior to that reached with a high-contrast neutral test-object.

In his contribution, dealing with some effects of filament and of fluorescent lighting on visual performance, Dr. W. F. Floyd, senior lecturer in physiology, Middlesex Hospital Medical School, London, presented the results of a number of tests applied to clerical workers subjected to these forms of lighting alternately. Among the questions which have been posed concerning fluorescent lighting, that of its efficiency as a visual stimulus is one to which an answer is of particular interest to large employers of labour, who must provide artificial lighting on a large scale. Another question is what, if any, is the effect of the usually unnoticeable cyclic variation in light output of fluorescent lamps? Dr. Floyd's investigations were primarily intended to find an answer to these two questions.

Dr. Floyd first made an experiment with twentytwo persons of normal sight, who performed Weston's speed of visual discrimination test illuminated to $10 \mathrm{~lm} . / \mathrm{ft} .{ }^{2}$ alternately by filament lamps and by fluorescent lamps. The mean performance of the subjects under each illuminant did not differ significantly. Multiple tests of a similar kind were then performed by another group under $6 \mathrm{~lm}$. $/ \mathrm{ft} .{ }^{3}$ of filament lighting and also under $6 \mathrm{~lm}$./ft. ${ }^{2}$ of fluorescent lighting; again there was no significant difference between the respective mean performances. In another experiment, seventeen persons were exposed to lighting which was automatically and instantaneously changed from filament to fluorescent at intervals of a few seconds. The filament lighting provided a fixed illumination, but the illumination given by the fluorescent lamps could be varied by the subjects, who were asked to match it to the filament lighting for 'equal comfort'. The mean level of fluorescent lighting chosen in this way was slightly higher than the control level, although the difference was physiologically insignificant.

So as to make a long-term comparison between flament and fluorescent lighting, three comparable groups of clerical workers carried out their normal daily work, interspersed with various tests of performance and of certain visual functions, for thirteen weeks under three forms of lighting. One group had filament lighting, another had fluorescent lighting operated by an a.c. power supply and the third group had d.c.-operated fluorescent lighting free from cyclic væriations. The working illumination in each office was standardized at $12 \mathrm{~lm}$./ft. ${ }^{2}$. None of the tests applied to the three groups afforded any evidence that the three forms of lighting had different effects. Thus, from all these experiments, it appears that, for equal illumination, visual performance is just as good under fluorescent lighting, with or without 'flicker', as it is under filament lighting.

Discussing the lighting of streets and vehicles, J. G. Holmes, technical director of Holophane, I.td., pointed out that its function is to give road users confidence in their visual impressions as trustworthy guides to action. In a suitable state of adaptation, the sensitivity of the eye to light is remarkable ; but, while very low illumination may enable familiar objects to be recognized fairly quickly, the rapid recognition of unfamiliar and unexpected objects, which is often essential for the safety of road users at night, requires much better illumination. An almost instantaneous assessment of the quickly changing scene confronting both pedestrian and vehicle driver has to be made and suitable motor responses initiated.

Under modern conditions in busy traffic areas, there is a bewildering variety of lights, among which those intended to give vital information or warning to road users sometimes lack conspicuity or add to the general confusion. The essential information should be given clearly with the right emphasis, and misleading information must be avoided. The variety of suitable colours and shapes of road signal lights seems now to be exhansted, hence the recent recourse to flashing lights so as to achieve conspicuity.

There is a tendency to increase the power of lights to gain attention to them, but this device also increases dazzle. An example is the red 'stop' lights on numerous modern cars. Some of these are of 100 candelas or more, and this is out of proportion to the general level of street lighting. They appear with shattering suddenness, often only a few yards in front of a following vehicle driver, and they tend to promote irritation and strain rather than visual confidence. Flashing beacons at pedestrian crossings give a welcome and timely warning of the need for special care; but where a number of them are visible at multiple road junctions they are disconcerting if out of step. Flashing car-direction lights take longer to interpret than semaphore indicators.

Mr. Holmes directed attention to the importance of siting street lamps so as to define the direction of roads unambiguously and to reveal the presence of roundabouts and centre reservations. Although improved street lighting tends to encourage greater traffic density and somewhat higher vehicle speeds, there is some statistical evidence that the night 
accident-rate is reduced, and there is no doubt that it increases the confidence of road users. As to the question of yellow versus white headlamps, careful experiments have led to the conclusion that, for equal beam intensity, there is no significant difference in revealing power nor in estimates of glare, and it is not true that yellow light penetrates fog better than white.

The general discussion evoked by the papers which have been summarized was confined to the subjects of fluorescent and of street and vehicle lighting. The chairman, Dr. R. S. Creed, mentioned that difficulty in reading meniscus gauges under fluorescent lighting was within his knowledge, although this may have been due simply to misplecement of the lights. Dr. Floyd pointed out that lamps of different colour temperature give different colour-rendering and, occasionally, a critical contrast might be weakened by the light from one type of lamp although not by another. He had investigated a variety of complaints against fluorescent lighting, but they were often expressions of dissatisfaction with other conditions, or they were due to conditions of lighting not necessarily produced by using fluorescent lamps. In reply to speakers who asked whether ocular illeffects resulted from long-term exposure to fluorescent lighting, Mr. Weston said that there is no evidence of this. There had been a few cases of ocular affections occurring soon after a change from filament to fluorescent lighting, and those affected had wrongly blamed the lighting; he mentioned one such case which was demonstrably due to a bacterial infection. When, as now, many changes to fluorescent lighting are taking place, it would be surprising if there were no merely coincidental occurrences of ocular troubles. From his own investigations, he could confirm Dr. Floyd's conclusion that complaints against fuorescent lighting often proved to have a different basis. Referring to flashing beacons at pedestrian crossings, a speaker thought it unfortunate that they do not adequately illuminate anyone using or waiting to use the crossing. As to the red 'stop' lights on cars, another speaker claimed that experiments have demonstrated that these should be of 50 candelas for seeing at a distance of $\mathbf{5 0}$ yards when a driver is dazzled by opposing headlights.

\section{GENETICS AND PLANT BREEDING}

A JOINT session at Bristol of Sections K (Botany) and $M$ (Agriculture) of the British Association was devoted to a symposium on "Genetics and Plant Breeding". The range of contributions to the symposium emphasized not only the scientific bases of present-day plant-breeding programmes, but also the dependence of advanced communities on a constant, integrated attack on those limiting factors to yield and quality which can be overcome by the genetical approach to crop improvement. A guaranteed standard of living, which advanced peoples have come to regard as a birthright, and which is now recognized as an international responsibility so far as the less-developed peoples are concerned, demands maximum efficiency from the germ plasm in food production. Not only must crop plants produce maximum yields at economic levels, but also quality, variety and long-term reliability of the material in the face of epidemics and environmental variations must also be among their attributes. The interaction of food production and soil fertility over large areas of the world presents grievous problems which can only be solved satisfactorily by escaping from an exhaustive form of monoculture to a rotational culture based on species of plants yet to be isolated from Nature's repertoire. If it is to continue to serve advanced communities, the science of plantbreeding has to respond quickly to human progress in all directions, in changes of dietary needs, in advances in agronomy, in farm mechanization as well as in the grading and processing of the final product.

Dr. D. Lewis, of the John Innes Horticultural Institution, Bayfordbury, in his opening paper, suggested how genetics, although unable to produce plants to order, can offer a systematic approach towards such problems and possibilities by initially 'blue printing' the foundation genotypes as well as outlining methods whereby a desired genetic architecture can be constructed stepwise. The limits to the construction of gene recombinations are frequently set by close linkage, involving gene effects with opposing or compensating functions. The eventual attainment of genotypes as near as possible to the ideal often depends on the breakdown of these linked units of inheritance. This problem is one with which crop-improvement projects are constantly being faced, and reliable methods such as a temporary passage through a tetraploid condition or the application of physical environmental stresses at meiosis might profitably be perfected to achieve an immediate and permanent release of undesirable gene combinations. Similarly, the breakdown of the natural breeding system of a species can often aid materially in releasing variability as well as in ensuring reliability of cropping. Thus in cherries, mutations induced by $\mathrm{X}$-rays have yielded fully self-fertile genotypes which crop well even under adverse conditions for pollination by insects.

The importance of the part played by the breeding system in controlling variability and therefore in deciding the genetical approach to its improvement is nowhere better exemplified than in the genus Rubus, which was surveyed by Dr. G. M. Haskell (John Innes Horticultural Institution, Bayfordbury). Here apomixis is widespread, but in some instances variations in the mechanism allow of segregation and recombination among maternal chromosomes. Such sub-sexual processes give rise to greater variability than is often realized, and selection becomes possible. The segregation of quantitative characters within the sub-sexual apomict $R$. nitidioides (Merton Early) indicates that the improvement of economic characters such as earliness and intensity of prickles is possible, though the speed of selection will necessarily be slower than in fully sexual groups. Many apomictic species are also polyploids of various kinds, and a complete change to sexuality may reveal an unbalance characteristic of some polyploid groups. Thus in the Eubatus section of Rubus, broadly divisible into the mainly tetraploid group Moriferi veri, and the Corylifolii, which are largely pentaploid and are descended from the apomictic $R$. caesius, apomixis is widespread ; whereas in the section Idaeobatus, consisting predominantly 